THE INTERNATIONAL

REVIEW OF RESEARCH IN

OPEN AND DISTANCE LEARNING

\title{
Building an Inclusive Definition of E-Learning: An Approach to the Conceptual Framework
}
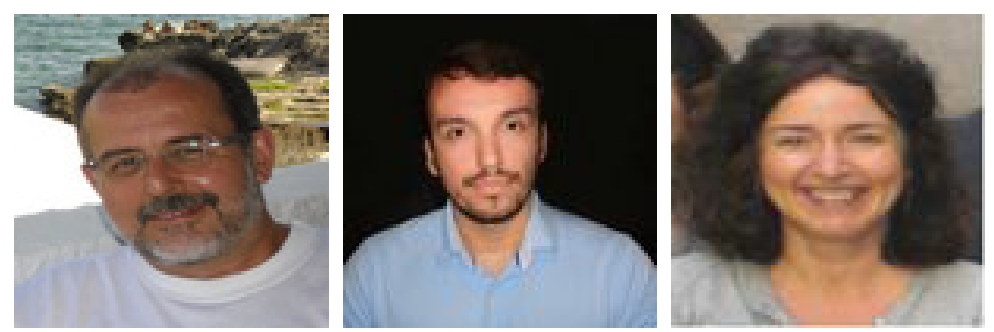

Albert Sangrà, Dimitrios Vlachopoulos, and Nati Cabrera Universitat Oberta de Catalunya, Spain

\section{Abstract}

E-learning is part of the new dynamic that characterises educational systems at the start of the $21^{\text {st }}$ century. Like society, the concept of e-learning is subject to constant change. In addition, it is difficult to come up with a single definition of e-learning that would be accepted by the majority of the scientific community. The different understandings of e-learning are conditioned by particular professional approaches and interests.

An international project, based on the participation of experts around the world, was undertaken to agree on a definition of e-learning. To this end, two main research activities were carried out. First, an extensive review was conducted of the literature on the concept of e-learning, drawing from peer-reviewed journals, specialised web pages, and books. Second, a Delphi survey was sent out to gather the opinions of recognised experts in the field of education and technology regarding the concept of e-learning with a view to reaching a final consensus.

This paper presents the outcomes of the project, which has resulted in an inclusive definition of e-learning subject to a high degree of consensus that will provide a useful conceptual framework to further identify the different models in which e-learning is developed and practiced.

Keywords: E-learning; definition; distance education; technology-enhanced education 


\section{Introduction}

In recent decades, the use of information and communication technologies (ICT) for educational purposes has increased, and the spread of network technologies has caused elearning practices to evolve significantly (Kahiigi et al., 2008). However, any definition of elearning must settle the issue of what is and what is not e-learning (Guri-Rosenbilt, 2005). The multiplicity of perspectives surrounding e-learning causes confusion and, sometimes, even contradictions (Mason \& Rennie, 2006). Not only have different concepts been attributed to e-learning, but the term has also been substituted by others, such as computerbased learning, technology-based training, and computer-based training, which actually predate the first mention of e-learning in the mid-1990s (Friesen, 2009) or the more recent online learning. Moreover, some people confuse the concept of e-learning with the concepts of a virtual campus or online courses, which can be part of the e-learning universe but do not sufficiently define it.

The evolution of distance education, as a result of new technologies and the contributions of computer scientists to the field of education along with the conceptualisation of education as a lifelong process, poses a major challenge for educational institutions: how to integrate these technologies into their organisation and, especially, into their teaching. From simple occasional use of ICT to reinforce face-to-face teaching and learning to the use of virtual environments for courses conducted completely online according to a variety of educational models, the incorporation of ICT into the learning process is being achieved from very different perspectives and through an extensive range of formulas, albeit with one common denominator: the use of practices whose origin and pedagogical foundations lie in distance education.

The discussion of the definition and practices of e-learning focuses on the intersection of education, teaching, and learning with ICT (Friesen, 2009). It is undoubtedly preceded by two other disciplines: educational technology and distance education. Both have significantly contributed to the intensive use of ICT for educational purposes, but neither can be strictly equated with e-learning.

E-learning could also be considered a natural evolution of distance learning, which has always taken advantage of the latest tools to emerge in the context of technologies for structuring education. In fact, some authors consider e-learning to be a new generation of distance education, even as they point to significant differences between the two and highlight a key starting point: "E-learning does not represent more of the same (...) [It is] about doing things differently" (Garrison \& Anderson, 2003, p. 7).

However, the suspicion that different meanings or definitions of e-learning are conditioned by particular professional approaches and, more importantly, by particular individual or corporate interests underscores the need to analyse this field of knowledge.

Studies attempting to provide inclusive, or umbrella, definitions of concepts are quite common in the social sciences and psychology (Castle, 2000; Eagly \& Chaiken, 2007; Jones, 
1999; Waddington, Badge, \& Bull, 2005). In the educational sciences, studies from different knowledge areas can also be found that aim to define concepts used with different meanings by the scientific community (Allen, 2004; Baker, 1979; Garavan, 1997; Stanovich, 1998; Wright, 2002). Finally, it is worth noting that in the field of distance education, important studies have been conducted with a view to defining similar concepts to e-learning (Keegan, 1980, 1988; Garrison \& Shale, 1987). These studies offer proof that there has, since the very emergence of distance education, been a need to create a common frame of reference for it.

An agreement on how to define e-learning could help research and researchers go forward in identifying models and practices for applying e-learning and in determining the key factors for better and more effective use of this type of teaching and learning: "There is a pressing requirement to understand better the nature of e-learning, as an educational innovation, and to evolve contextually derived frameworks for change which align with organisational culture and practice" (Rossiter, 2007, p. 93). The challenge of finding a single, inclusive definition of e-learning is the starting point for this study. As Renold and Barter (2003, p. 91) stated, an inclusive definition is "a broader definition that encompasses a wider spectrum of the concept and can cope with the complexity of its representation/characteristics."

\section{Research Design}

The main aim of this study was to create an inclusive definition of e-learning that would be accepted by the majority of the scientific community and would also define the boundaries for future activity in this sector. Two main research activities were carried out to achieve this aim.

1. An extensive literature review: Indexed and peer-reviewed journals, government reports, web pages, and books were considered and analysed. The main objective of this activity was to collect the available definitions of e-learning in order to compare and categorise them according to their main perspective and focus.

2. A Delphi survey: Online questionnaires were sent to recognised experts in the field of education and ICT in order to determine their perceptions of and beliefs regarding elearning with a view to reaching a final consensus and creating an inclusive definition. The entirety of this second research activity was monitored and evaluated by educational research methodology experts from the Netherlands, Spain, and Canada.

\section{Literature Review}

A literature review is understood as a description of the relevant literature on a particular field or topic (University of Canberra, 2006). The topics used for this review were e-learning and definition, and the search was performed in the field of education and ICT.

The search was limited to literature published in or after 2005 as for a new concept such as e-learning that is characterised by constant change, it was considered preferable to work with papers published in the last five years. However, definitions of e-learning dating from before 2005 were considered when designing the research as some of these definitions have 
provided the basis for newer ones.

Three main sources of literature were used for the review:

1. academic and scientific journals indexed in the Social Sciences Citation Index (ISI Web of Knowledge) in or after 2005;

2. books and book chapters, government reports, and doctoral dissertations related to education and ICT and e-learning, published in or after 2005; and

3. open virtual spaces (e.g., blogs, institutional web pages, glossaries) by recognised authors, where education and ICT and e-learning are analysed and discussed.

The definitions gathered from the literature review focus on different elements of e-learning. Specifically, four general categories of definitions were identified: 1) technology-driven, 2) delivery-system-oriented, 3) communication-oriented, and 4) educational-paradigmoriented.

\section{Technology-Driven Definitions}

This category mostly includes definitions from private companies and a few academics that emphasise the technological aspects of e-learning, while presenting the rest of its characteristics as secondary. The definitions in this category portray e-learning as the use of technology for learning. Representative samples of this category include the following.

- $\quad$ "E-learning is the use of electronic media for a variety of learning purposes that range from add-on functions in conventional classrooms to full substitution for the face-toface meetings by online encounters" (Guri-Rosenblit, 2005).

- "E-learning is to take a course online using a modem, wireless, or cable connection to access academic course material from a computer, phone, or handheld device" (Governors State University, 2008).

- "E-learning is distance education through remote resources" (Marquès, 2006).

- "E-learning is the use of technology to deliver learning and training programs" (Elearning portal, 2009).

\section{Delivery-System-Oriented Definitions}

This category presents e-learning as a means of accessing knowledge (through learning, teaching, or training). In other words, the focus of these definitions is the accessibility of resources and not the results of any achievements. Representative samples from this category include the following.

- "E-learning is the delivery of education (all activities relevant to instructing, teaching, and learning) through various electronic media” (Koohang \& Harman, 2005). 
- "E-learning is an on-line education defined as the self-paced or real-time delivery of training and education over the internet to an end-user device" (Lee \& Lee, 2006).

- "E-learning is the delivery of a learning, training or education program by electronic means" (Li, Lau \& Dharmendran, 2009).

- "E-learning is defined as education delivered, or learning conducted, by Web techniques" (Liao \& Lu, 2008).

\section{Communication-Oriented Definitions}

This category considers e-learning to be a communication, interaction, and collaboration tool and assigns secondary roles to its other aspects and characteristics. Representative examples of these definitions, which come mostly from the academic and communication sectors, include the following.

- "E-learning is education that uses computerised communication systems as an environment for communication, the exchange of information and interaction between students and instructors" (Bermejo, 2005).

- "E-learning is learning based on information and communication technologies with pedagogical interaction between students and the content, students and the instructors or among students through the web" (González-Videgaray, 2007).

- "E-learning is defined as learning facilitated by the use of digital tools and content that involves some form of interactivity, which may include online interaction between the learner and their teacher or peers" (Ministry of Communication and Technology of New Zealand, 2008).

\section{Educational-Paradigm-Oriented Definitions}

This category defines e-learning as a new way of learning or as an improvement on an existing educational paradigm. The majority of the authors falling into this category work in the education sector. Some of the most representative examples of these definitions include the following.

- "E-learning is the use of new multimedia technologies and the Internet to improve the quality of learning by facilitating access to resources and services, as well as remote exchange and collaboration" (Alonso et al., 2005).

- "E-learning is a broad combination of processes, content, and infrastructure to use computers and networks to scale and/or improve one or more significant parts of a learning value chain, including management and delivery" (Aldrich, 2005).

- "E-learning is defined as information and communication technologies used to support students to improve their learning" (Ellis, Ginns \& Piggott, 2009).

- "E-learning refers to educational processes that utilise information and communica- 
tions technology to mediate synchronous as well as asynchronous learning and teaching activities" (Jereb \& Šmitek, 2006).

\section{Survey of Expert Opinions}

A Delphi survey was used to determine experts' perceptions and knowledge with a view to reaching a final consensus. This method makes it possible to deal with complex problems (Linstone \& Turoff, 1975), such as the creation of an inclusive definition of e-learning.

Delphi studies are considered particularly useful in the field of pedagogy (Yousuf, 2007). Rieger (1986) reported that $83 \%$ of the PhD theses completed between 1981 and 1984 used the Delphi technique and concluded that "it seems reasonable to claim that Delphi is continuing to be a much used tool in the search for answers to normative questions, especially in education areas" (p. 198). The Delphi technique, it should be noted, is also widely used in the field of emerging education technologies. Some of the most important studies in this field based on leveraging established expertise to provide the input for and inform such analyses include the NMC Horizon Report series by the New Media Consortium and the Educause Learning Initiative (Johnson, Smith, Willis, Levine, \& Haywood, 2011), the Future of the Internet Report series by the Pew Internet \& American Life Project and Elon University (Anderson \& Rainie, 2008) and the Top Teaching and Learning Challenges 2009 project by Educause (Little \& Page, 2009).

Online questionnaires were sent to recognised experts in the field of education and ICT. Experts was understood to refer to people who are partially or fully devoted to conducting research in this field and have published their findings in journal articles, books, government reports, theses, and dissertations. The main purpose of the survey was to determine their perceptions of the e-learning concept. They were asked to define the e-learning concept, to name its main components, and to categorise it among the scientific fields.

Following a pilot Delphi round, two more rounds were carried out. The surveys contained open and closed questions, and respondents were asked to give spontaneous but reasoned answers. The pilot round was used to validate the questionnaire with the participation of experts in the fields of educational research methodology and education and ICT from the Netherlands, Spain, and Canada. Some minor modifications were made based on their recommendations.

The first survey round contained a total of 15 questions and was divided into two main parts. The first part consisted of 10 demographic questions related to the experts' age, place of residence, sex, studies, academic profile, professional experience in e-learning, and contact details. The second part included a brief summary of the review of the literature on the e-learning concept, including a description of the four general definition categories mentioned above. Following this introduction, five questions asked the experts for their opinion about the conceptual framework of e-learning in relation to the different categories identified in the literature review. A Likert scale from 1 to $5(1=$ does not represent the e-learning concept; 5 = represents the e-learning concept exactly) was provided to answer the first 
question.

The second question complemented the first since the experts were asked to justify their previous evaluation and to explain whether they believed that there was a single category able to offer an inclusive definition of e-learning. The third and fourth questions asked whether they believed there was any other category of e-learning definitions that had not been mentioned in the survey. If so, they were asked to name it and to describe its main characteristics. Finally, the last question offered the participating experts an open space for comments.

Based on the above definition of expert and with a view to including participants from all continents, an initial list of a total of 103 experts was drawn up. During the first round, 33 experts answered the survey ( $32 \%$ of the initial population), a number considered satisfactory for an anonymous study conducted online. Table 1 shows the geographical distribution of the experts.

Table 1

Geographical Distribution of the Participating Experts

\begin{tabular}{|l|l|l|l|}
\hline Spain (7) & Greece (1) & France (1) & Puerto Rico (1) \\
\hline Norway (1) & Switzerland (1) & USA (2) & Japan (1) \\
\hline Germany (1) & United Kingdom (1) & Canada (4) & Australia (1) \\
\hline Italy (1) & Netherlands (1) & Brazil (1) & New Zealand (1) \\
\hline \multicolumn{4}{|l}{ Total: 33 experts (14 women; 19 men) } \\
\hline
\end{tabular}

The majority of the experts (85\%) were over the age of 45 . While they had different educational backgrounds, most had an educational profile. With regard to their current occupation, $85 \%$ of the participants work as academics or research staff at higher education institutions, while the remaining $15 \%$ come from the corporate sector. As for the four definition categories, most respondents (85\%) felt that the educational paradigm category best represents the conceptual framework of e-learning. Figure 1 shows the average scores they assigned.

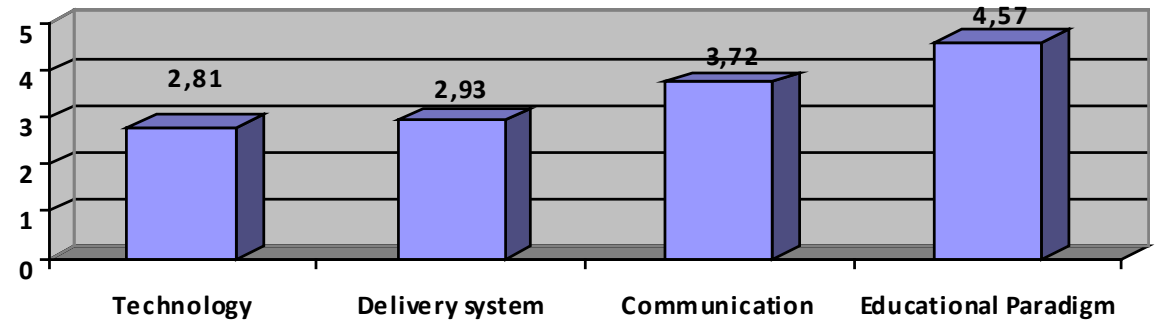

Figure 1. Evaluation of the four definition categories by the participating experts $(1=$ does not represent the e-learning concept; 5 = represents the e-learning concept exactly). 
In addition to their evaluations, the experts provided some very useful comments regarding how e-learning should be defined and offered important arguments to be considered with regard to the construction of an inclusive definition. Their contribution can be summarised in four main points.

1. The quickly changing nature of the uses of technology for teaching and learning must be taken into consideration when preparing a definition of e-learning.

2. E-learning can be used not only for collaborative learning, but also for autonomous, individual learning.

3. E-learning is a means of facilitating the achievement of (formal or informal) learning goals.

4. E-learning is a new learning/training model, a new way to learn.

In the second round, the experts were encouraged to revise their earlier answers in light of the responses of the other members of the panel. Over the course of this process, the degree of disagreement was expected to decrease and the group was expected to converge towards an agreed statement.

Nevertheless, they were encouraged to change their opinions only if they agreed with the most popular answer and were convinced that it was the most suitable one. Since no major differences were found among the experts' arguments and comments regarding the creation of an inclusive definition of e-learning, it was considered that one more round would be enough to reach a final consensus.

In this context and after taking into consideration all their comments and arguments, a preliminary definition of e-learning was prepared, containing aspects of all four general categories. The experts were asked to evaluate it in the final Delphi round. The preliminary definition was as follows:

E-learning is an approach to teaching and learning, representing all or part of the educational model applied, that is based on the use of electronic media and devices as tools for improving access to training, communication and interaction and that facilitates the adoption of new ways of understanding and developing learning.

In the final round, experts were asked to use a Likert scale from 1 to 4 ( $1=$ the definition does not represent the e-learning concept; 2 = the definition hardly represents the e-learning concept; 3 = the definition represents the e-learning concept fairly well; 4 = the definition fully represents the e-learning concept) to express either agreement (3/4) or disagreement (1/2) and to check whether their comments had been successfully incorporated into the final inclusive definition. The level of acceptance of the definition turned out to be quite high, with 31 of the 33 participants evaluating it positively (3/4), for an average score 
of 3.40. Figure 2 shows the breakdown of the scores.

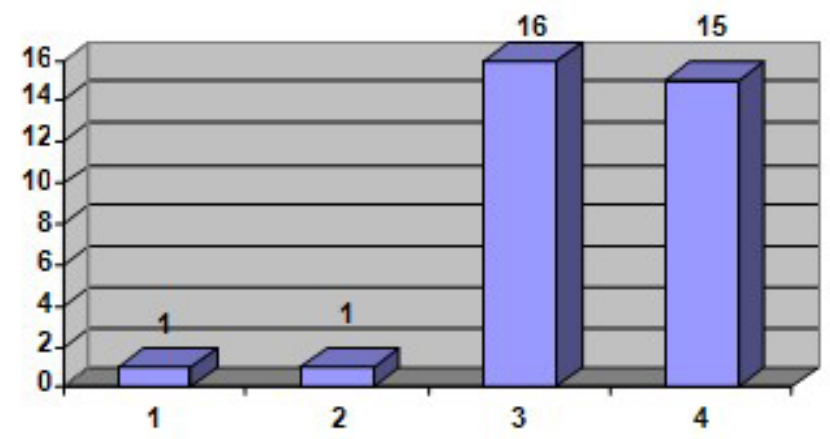

口How would you evaluate our inclusive definition?

Figure 2. Evaluation of the inclusive definition by the participating experts.

Although the consensus regarding this definition was quite strong, the participating experts insisted on two basic aspects that should be revisited:

1. The evolution of the technologies used for learning and teaching should be taken into consideration;

2. The e-learning concept is also based on certain socioeconomic factors that may not need to be explicitly included in the definition but should nevertheless be taken into account.

\section{Limitations of the Study}

Although this study was carried out according to the methodology recommended by experts in educational research, certain limitations should be pointed out.

In spite of the fact that the ISI Web of Knowledge database is considered one of the most prestigious databases in the world, it does not include all the most important publications on e-learning, probably due to the newness of the concept and an existing policy against open access journals, which are increasingly used to distribute research on e-learning (Anderson \& McConkey, 2009). Thus, some interesting definitions of the e-learning concept published in other relevant journals may have been overlooked.

Additionally, despite the satisfactory number of participating experts, the sample of experts from Asia and Africa was not as large as expected, perhaps due to the strict time constraints of the research.

\section{Conclusions and Further Research}

The results of this study confirm its main research hypothesis about the difficulty of devising a single, inclusive definition of e-learning that would be accepted by the majority of the scientific community due to the existence of different perspectives on this concept based on authors' professional and academic profiles. It was found that the most important reasons for this situation are that both the concept of e-learning and society are in a state of con- 
stant flux and the term is understood from many angles and used with different meanings (Stein, Shephard, \& Harris, 2011).

After the analysis of the contributions of the participating experts, the research arrived at the general conclusion that e-learning is part of the new dynamic that characterises educational systems at the start of the $21^{\text {st }}$ century, resulting from the merge of different disciplines, such as computer science, communication technology, and pedagogy, since all the collected definitions contained characteristics of more than one discipline. Consequently, the concept of e-learning can be expected to continue to evolve for a long time. In today's world, learning needs change very quickly and the concept and functions of e-learning must continuously be adapted to these needs.

Moreover, the difficulty to include all the main features of the e-learning concept in a single definition was identified since not all authors made the same use of the concept and they considered different aspects as fundamental. In this context, and in order to take advantage of all the definitions created, the need to be flexible and generic enough to include the majority of these uses and features is considered compulsory. More analytically, this study resulted in an inclusive definition that takes into consideration the four main categories in which authors conceptualise e-learning: technology, delivery systems, communication, and educational paradigms.

It is true that there is a risk in adopting an inclusive definition of e-learning because this definition connects its different elements and features, which can obstruct the understanding of the concept. But the commonality that unites the concepts is also important, and this can be shown only through an inclusive definition which presents the different interrelated features (Waddington, Badger, \& Bull, 2005).

As far as the different tendencies of the created definitions of e-learning are concerned, it was found that authors with a more technological profile geared their definitions towards technology or access systems, while authors with an educational profile focused on the new educational paradigm and communication. The participation of e-learning experts from different approaches that agreed on this inclusive definition will help enormously to make easier its acceptance. On the other hand, the new definition is not threatening any practices. It wants to be a common framework for enhancing theory development and empirical research in a community of scientists (Eagly \& Chaiken, 2007) and, in this case, developing further research in identifying e-learning application models.

Another conclusion derived from the findings of this study is that e-learning goes far beyond technology, even though the concept did not appear until after computers began to be used in education. The literature review and the Delphi method applied to the participating experts showed that e-learning also refers to the actual learning that takes place when these resources are used. In this regard, the experts mainly characterised e-learning as a "way of teaching and learning" moving towards a "new educational paradigm."

In addition, the framework provided by Jones (1999) is confirmed since this study em- 
braced a broad and inclusive definition of e-learning in the belief that e-learning is an important - indeed, a key - issue for all academics and professionals who work and do research in the field of education and ICT. As a result, an inclusive definition of this concept enables multiple points of entry into the discussion of e-learning, from its basic components to its application and models. In other words, a greater number of individuals will see the relevance of, and their personal connection to, the concept and will thus be able to access different points of the discussion and implementation. Since e-learning is often perceived as being too abstract for people to understand, an inclusive definition can be used to provide the basis, and language, for understanding one's own connection to the field. It is believed that this new definition of the concept could serve as the first step to establishing a new framework of reference for e-learning able to boost research activity by providing a common starting point.

Furthermore, the purpose of the new definition is to consider e-learning as a more comprehensive concept, in which bias due to the four identified categories leads to identifying different models of application but does not extend to the concept itself. The most important advantage is to avoid discussions about the extent to which some practice is e-learning or is not. The core question will explain which kind of e-learning model is being applied and what its aims and potential benefits are in a particular context. This should help give the e-learning concept more consistency, which will enable working on the establishment of a pattern for analysing e-learning models that should result in more arguments in favour of the potential achievements of e-learning.

Finally, the contribution of an inclusive definition to the evolution of terminology shouldn't be ignored. The importance of updating different concepts was underlined many years ago (Allport, 1935) since it helps to reach a convergent point to start a new journey on the concept.

As Bates and Poole (2003) suggested, it would also be worth considering that there are different types or forms of e-learning and even different models of applying it. Further research should also focus on both the specific and common characteristics of these e-learning models and on the contexts in which they might work best. 


\section{References}

Aldrich, C. (2005). Simulations and the future of learning: : An innovative (and perhaps revolutionary) approach to e-learning. San Francisco: Pfeiffer.

Allen, L. (2004). Beyond the birds and the bees: Constituting a discourse of erotics in sexuality education. Gender and Education, 16(2), 151-167.

Alonso, F., López, G., Manrique, D., \& Viñes, J. M. (2005). An instructional model for web-based e-learning education with a blended learning process approach. British Journal of Educational Technology, 36(2), 217-235.

Allport, G.W. (1935). Attitudes. In C. Murchison (Ed.), Handbook of social psychology (pp. 798-844). Worcester, MA: Clark University Press.

Anderson, T., \& McConkey, B. (2009). Development of disruptive open access journals. Canadian Journal of Higher Education, 39(3), 71-87.

Anderson, J. Q., \& Rainie, L. (2008). The future of the Internet III. Washington, DC: Pew Internet \& American Life Project. Retrieved from http://www.pewinternet.org/ pdfs/PIP_FutureInternet3.pdf

Baker, D.B. (1979). Severely handicapped: Toward an inclusive definition. AAESPH Review, 4(1), 52-65.

Bates, A., \& Poole, G. (2003). Effective teaching with technology in higher education. San Francisco: Jossey-Bass/John Wiley.

Bermejo, S. (2005). Cooperative electronic learning in virtual laboratories through forums. IEEE Transactions on Education, 48(1), 140-149.

Castle, D. (2000). Limitations of an inclusive definition of ecosystem-health. Ethics, 5(2), 153-161.

E-learning Portal (2009). E-learning glossary. Retrieved from http://www.e-learningguru.com/glossary/e.htm.

Eagly, A.H., \& Chaiken, S. (2007). The advantages of an inclusive definition of attitude. Social Cognition, 25(5), 582-602.

Ellis, R. A., Ginns, P., \& Piggott, L. (2009). E-learning in higher education: Some key aspects and their relationship to approaches to study. Higher Education Research \& Development, 28(3), 303. Retrieved from http://www.informaworld. com/10.1080/07294360902839909.

Friesen, N. (2009). Re-thinking e-learning research: Foundations, methods and practices. New York: Peter Lang. 
Garavan, T.N. (1997). Training, development, education and learning: Different or the same? Journal of European Industrial Training, 21(2), 39-50.

Garrison, D.R., \& Anderson, T. (2003). E-learning in the $21^{\text {st }}$ century. A framework for research and practice. London: RoutledgeFalmer.

Garrison, D.R., \& Shale, D. (1987). Mapping the boundaries of distance education: Problems in defining the field. American Journal of Distance Education, 1(1), 7-13.

González-Videgaray, M. (2007). Evaluación de la reacción de alumnos y docentes en un modelo mixto de aprendizaje para educación superior. RELIEVE, 13(1) Retrieved from http://www.uv.es/RELIEVE/v13n1/RELIEVEv13n1_4.htm.

Governors State University, Center for Online Learning and Teaching. (2008). E-learning glossary. Retrieved from www.govst.edu/elearning/default.aspx.

Guri-Rosenblit, S. (2005). 'Distance education'and 'e-learning': Not the same thing. Higher Education, 49(4), 467-493.

Jereb, E., \& Šmitek, B. (2006). Applying multimedia instruction in e-learning. Innovations in Education \& Teaching International, 43(1), 15-27.

Johnson, L., Smith, R., Willis, H., Levine, A., \& Haywood, K. (2011). The 2011 Horizon report. Austin, Texas: The New Media Consortium.

Jones, D.E. (1999). “The definition of diversity: Two views. A more inclusive definition. In M. Winston (Ed.), Managing multiculturalism and diversity in the library. USA: Haworth Press.

Kahiigi, E.K., Ekenberg, L., Hansson, H., Tusubira, F.F., \& Danielson, M. (2008). Exploring the e-learning state of the art. The Electronic Journal of e-Learning, 6 (2), 77-88. Retrieved from http://www.ejel.org

Keegan, D. (1980). On defining distance education. Distance Education, 1(1), 13-36.

Keegan, D. (1988). Problems in defining the field of distance education. American Journal of Education, 2(2), 4-11.

Koohang, A., \& Harman, K. (2005). Open source: A metaphor for e-learning. Informing Science Journal, 8, 75-86.

Lee, T., \& Lee, J. (2006). Quality assurance of web based e-learning for statistical education. COMPSTAT: Proceedings in Computational Statistics: 17th Symposium, Rome.

Li, F. W., Lau, R. W., \& Dharmendran, P. (2009). A three-tier profiling framework for adaptive e-learning. Proceedings of the 8th International Conference on Advances in Web Based Learning, Aachen. 
Liao, H., \& Lu, H. (2008). Richness versus parsimony antecedents of technology adoption model for E-learning websites. Retrieved from http://dx.doi.org/10.1007/978-3540-85033-5_2.

Linstone, H.A., \& Turoff, M. (Eds.) (1975). The Delphi method: Techniques and application. Retrieved from http://is.njit.edu/pubs/delphibook/.

Little, J.K., \& Page, C. (2009). Charting the course and tapping the community: The EDUCAUSE top teaching and learning challenges 2009. Boulder: EDUCAUSE.

Marquès, P. (2006). Definición del e-learning. Retrieved from www.pangea.org/peremarques.

Mason, R., \& Rennie, F. (2006). Elearning: The key concepts. New york: Routledge

Ministry of Comunication and Technology of New Zealand. (2008). Digital strategy of the ministry of comunication and technology. Retrieved from www.digitalstrategy. govt.nz/Resources/Glossary-of-Key-Terms/.

Renold, E., \& Barter, C. (2003). Hi, I'm Ramon and I run this place: Challenging the normalisation of violence in children's homes from young people's perspective's. In E.A. Stanko (Ed.), The meaning of violence (pp. 90-111). London: Routledge.

Rieger, W.G. (1986). Directions in Delphi developments: Dissertations and their quality. Technological Forecasting and Social Change, 29, 195-204.

Rossiter, D. (2007). Whither e-learning? Conceptions of change and innovation in higher education. Journal of Organisational Transformation and Social Change, 4(1), 93-107.

Stanovich, K.E. (1998). Toward a more inclusive definition of Dyslexia. Dyslexia: An International Journal of Research and Practice, 2(3), 154-166.

Stein, S. J., Shephard, K., \& Harris, I. (2011). Conceptions of e-learning and professional development for e-learning held by tertiary educators in New Zealand. British Journal of Educational Technology, 42(1), 145-165.

University of Canberra. (2006). Writing a literature review. Retrieved from http://www. canberra.edu.au/studyskills/writing/literature.

Waddington, P.A.J., Badge, D., \& Bull, R. (2005). Appraising the inclusive definition of workplace violence. British Journal of Criminology, 45(2), 141-164.

Wright, T.S.A. (2002). Definitions and frameworks for environmental sustainability in higher education. International Journal of Sustainability in Higher Education, 3(3), 203-220. 
Yousuf, M.I. (2007). The Delphi technique. Essays in Education, 20, 80-89.

\section{Athabasca University $\mathbf{A}$}

(c) (7) 